\title{
Geometrical structure, vibrational spectra and thermodynamic properties of chitosan constituents by DFT method
}

\author{
Isaac Onoka ${ }^{*}$, Alexander Pogrebnoi, Tatiana Pogrebnaya \\ Dept. of Materials Science and Engineering, The Nelson Mandela African Institution of Science and Technology, Arusha, Tanzania
}

\section{Email address:}

onokaisaac@gmail.com (I. Onoka), alexander.pogrebnoi@nm-aist.ac.tz (A. Pogrebnoi), tatiana.pogrebnaya@nm-aist.ac.tz (T. Pogrebnaya)

\section{To cite this article:}

Isaac Onoka, Alexander Pogrebnoi, Tatiana Pogrebnaya. Geometrical Structure, Vibrational Spectra and Thermodynamic Properties of Chitosan Constituents by DFT Method. International Journal of Materials Science and Applications. Vol. 3, No. 4, 2014, pp. 121-128. doi: $10.11648 /$ j.ijmsa.20140304.11

\begin{abstract}
The interaction between glucosamine molecules has been studied theoretically. The geometrical structures of monomer (A), dimer (AA) and trimer (AAA) molecules of glucosamine were optimized and vibrational spectra were calculated by DFT/B3LYP method using GAMESS software (Firefly version 8.0.0). The theoretical vibrational spectra for the glucosamine dimer and trimer correspond well to the experimental IR spectrum of chitosan. The energies and enthalpies of association of $\mathrm{A}$ to form the dimer and trimer have been determined. The enthalpies of dimerization, $\mathrm{A}+\mathrm{A}=\mathrm{AA}+\mathrm{H}_{2} \mathrm{O}$, and trimerization, $\mathrm{AA}+\mathrm{A}=\mathrm{AAA}+\mathrm{H}_{2} \mathrm{O}$, are -48 and $-45 \mathrm{~kJ} / \mathrm{mol}$, respectively. The thermodynamic functions of the monomer, dimer, and trimer molecules of glucosamine have been calculated.
\end{abstract}

Keywords: Glucosamine, Glucosamine Oligomers, Chitosan, DFT, Hydrogen Bond

\section{Introduction}

The physical and chemical properties of compounds are attributable to their structural parameters and also the energy of the complexes. Experimental measurement of the structural parameters is limited due to the expenses and facilities that can give results with accurate precision. Computational molecular modeling has greatly accelerated success in the determination of structural parameters, vibrational frequencies, and also thermodynamic properties of complexes. As a modern technique of chemistry, its advent and popularity in the last several decades and improvements in the computing power help chemists to predict molecular structure, interactions and properties and eventually understand chemical reactions and processes.

Chitosan is a natural polysaccharide found in crabs, shrimps, lobsters, corals, jellyfish, butterflies, ladybugs, mushrooms and fungi. Marine crustaceans shells are widely used as primary sources of chitin [1]. Chitin is regarded as the second most abundant polymer that exists in nature after cellulose [2]. It is formed from the repeating units of acetylglucosamine and glucosamine that link to form a large polymer unit. It is made up of a $\beta(1-4)$-linked 2acetamido-2-deoxy- $\beta$-D-glucose (N-acetylglusosamine) [3]. Chitosan is a derivative of chitin polysaccharides consisting of varying amounts of $\beta(1-4)$-linked residues of N-acetyl-2 amino-2-deoxy-D-glucose [4]. It has a similar structure as the chitin but the difference between them is the deacetylation degree and their respective solubility in dilute acidic media $[5,6]$. A schematic chemical structure of a chitosan polymer is shown in Fig. 1.

Previously computation molecular modeling had been applied in the investigation of the interaction mechanism of chitosan constituents and heavy metals [7-9]. The aim of this work was to study the interaction between glucosamine molecules resulting in the dimer and trimer formation. The DFT method was applied to determine the structural parameters, vibrational spectra and thermodynamic properties of glucosamine oligomers.

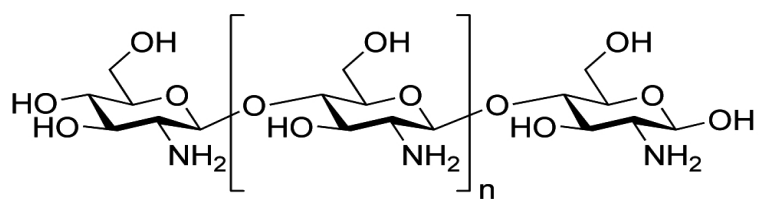

Figure 1. Schematic chemical structure of a deacetylated chitosan polymer. 


\section{Computational Methods}

The chitosan constituents considered in this study are denoted as A for the monomer, AA for the dimer and AAA for the trimer glucosamine molecules. The structural parameters of the A, AA, and AAA have been obtained using electron density functional theory (DFT) with the Becke-Lee-Yang-Parr functional (B3LYP) and polarized split-valence basis set 6-31G(d, p). Firefly Quantum Chemical package, version 8.0.0 [10] which is partially based on the GAMESS (US) source code [11] has been used. Firefly as a versatile computation package allowed us to determine the equilibrium structure, i.e. a structure that represents a minimum on a potential energy surface. With this calculation, the internal coordinates such as the internuclear distances, valence angles and the torsion angles, were obtained. This process was followed by a hessian calculation to calculate the vibrational spectra. In this step, the vibrational frequencies and IR intensities were computed.

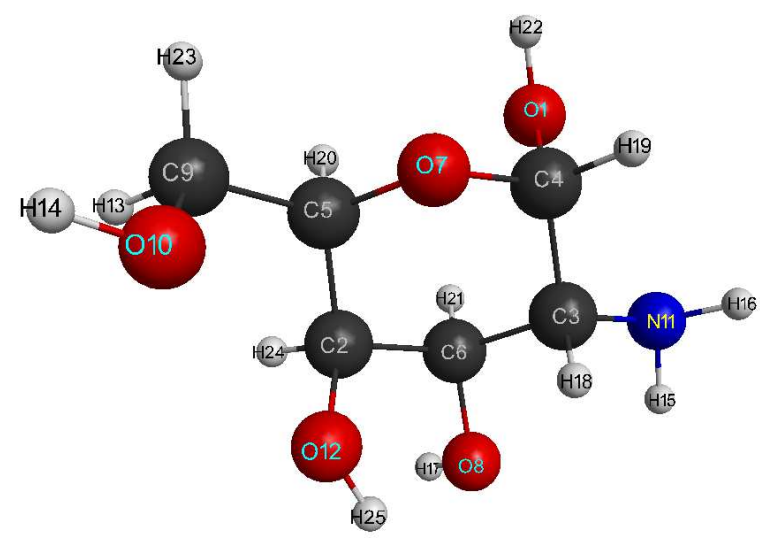

(a)
To display 3-D molecular structures and normal vibrational modes, the molecular visualization program wxMaclPlt [12] was used. Energies of the dimerization and trimerization reactions were computed using different basis sets: 6-31G(d,p), 6-31G++(d,p), and 6-311G++(d,p), the geometrical structures optimized with the basis set 6-31G(d,p) being used.

\section{Results and Discussion}

\subsection{Equilibrium Geometrical Structures}

The optimized geometrical structures of A, AA and AAA glucosamine molecules, presented in Figs. 2 (a), (b), (c), all belong to the $C_{1}$ point group symmetry. The most important selected geometrical parameters, namely the bond lengths, valence angles and torsion angles, are summarized in Tables 1-3.

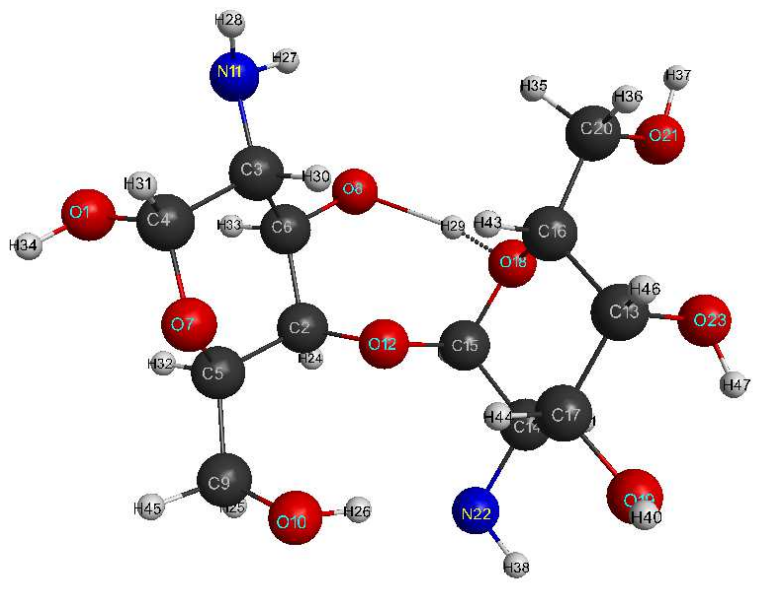

(b)

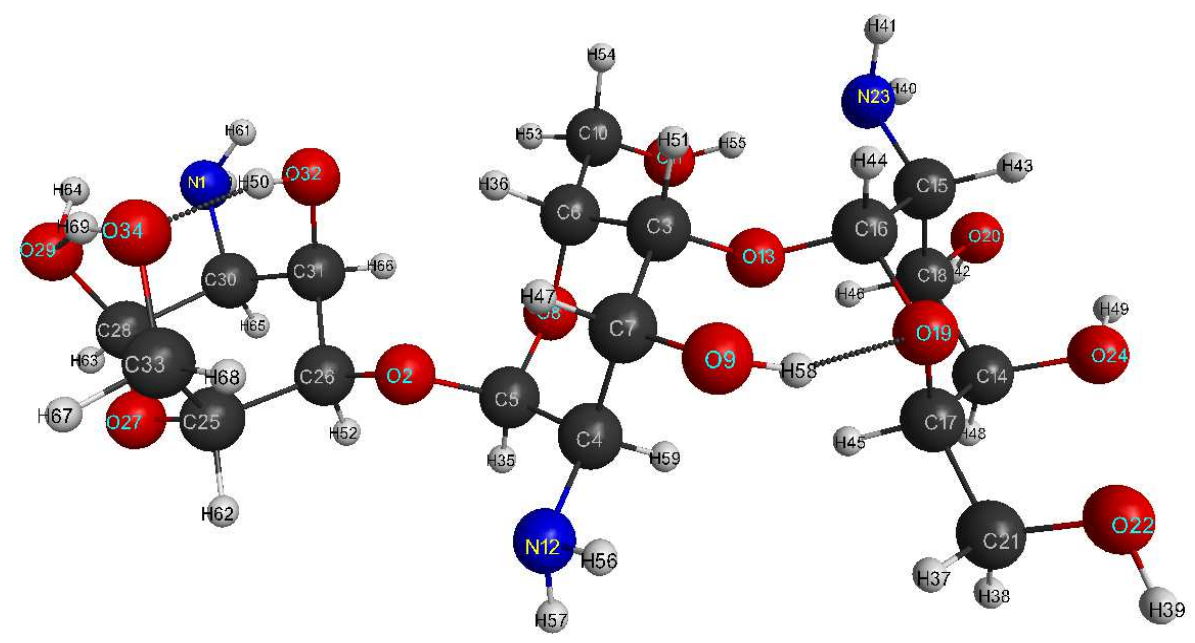

(c)

Figure 2. Equilibrium geometrical structure of the glucosamine molecules: monomer $A(a) A$, dimer (b), and trimer (c).

Each of the glucosamine molecules has six-atomic cycle with a ring oxygen atom inserted. All of these cycles in A,
AA, and AAA are not planar, as the sum of all six valence angles within the ring is much less than $720^{\circ}$; the values of 
the torsion angles confirm non-planarity of the cycles as well. In the monomer $\mathrm{A}$, the ring oxygen atom is attached between $\mathrm{C} 4$ and $\mathrm{C} 5$ making an angle $\mathrm{C} 4-\mathrm{O} 7-\mathrm{C} 5$ equal to $114^{\circ}$. In the dimer molecule $\mathrm{AA}$, the corresponding angles, C4-O7-C5 and C15-O18-C16 are also both equal to $114^{\circ}$. In the trimer AAA, the similar angles are a bit different i.e.: $111^{\circ}$ in the central ring, $112^{\circ}$, and $115^{\circ}$ in the side rings. The two $\mathrm{C}-\mathrm{O}$ internuclear distances regarding this $\mathrm{C}-\mathrm{O}-\mathrm{C}$ fragment are not equivalent; one is $\sim 1.42$ and the other is $\sim 1.44 \AA$.

In the dimer and trimer molecules the cycles are linked by the glycosidic bond C-O-C. As it is noted in [13] this bond is responsible for the stiffness and stability of the chitosan molecular structure. Both in AA and AAA, the two C-O internuclear distances are not equivalent within the same $\mathrm{C}-\mathrm{O}-\mathrm{C}$ fragment in the glycosidic bond. The shortest is about $1.40 \AA$ whereas the longest between 1.42-1.44 $\AA$. In AA the valence angle $\mathrm{C} 2-\mathrm{O} 12-\mathrm{C} 15$ is $119^{\circ}$ and the corresponding torsion angle $\mathrm{C} 2-\mathrm{O} 12-\mathrm{C} 15-\mathrm{C} 14$ is $138^{\circ}$. In $\mathrm{AAA}$, the valence angles $\angle \mathrm{C} 16-\mathrm{O} 13-\mathrm{C} 3=119^{\circ}$ and $\angle \mathrm{C} 5-\mathrm{O} 2-\mathrm{C} 26=117^{\circ}$; the torsion angles are $139^{\circ}$ and $146^{\circ}$ for $\mathrm{C} 3-\mathrm{O} 13-\mathrm{C} 16-\mathrm{C} 15$ and $\mathrm{C} 5-\mathrm{O} 2-\mathrm{C} 26-\mathrm{C} 25$ fragments respectively. In the trimer molecule, the glycosidic bridges are bent opposite to each other.

The $-\mathrm{NH}_{2}$ group is attached to the ring carbon atom and is located at the opposite side with respect to the $-\mathrm{CH}_{2} \mathrm{OH}$ group in each of the cycles of A, AA, and AAA molecules.
That is due to the mutual repulsion of both negatively charged $\mathrm{N}\left(q_{\mathrm{N}}=-0.60\right)$ and $\mathrm{O}\left(q_{\mathrm{O}}=-0.50\right)$ atoms in the $-\mathrm{NH}_{2}$ and $-\mathrm{CH}_{2} \mathrm{OH}$ group, respectively. In the neighboring rings of the dimer and trimer molecules, the amino groups occupy the opposite position to each other. It is generally accepted and remarkable to mention here that the amino groups of chitosan are responsible for its complexing with metal ions as the cations have a preference to ligands with the amino groups.

The average $\mathrm{C}-\mathrm{C}$ bond length in the monomer $\mathrm{A}$ is $1.535 \AA \mathrm{A}, 1.540 \AA$ in the dimer $\mathrm{AA}$ and $1.565 \AA$ in the trimer AAA molecule. These results show that there is a slight increase in C-C separation between two atoms of the rings as the polymer increases in complexity. Similar results were obtained by Liu and co-workers in their investigation of N-Acetyl-D-glucosamine [14]. The internuclear distance $\mathrm{C}-\mathrm{N}$ in A C3-N11 (1.461 $\AA$ ) is comparable to C-N bond in AA C3-N11 (1.457 $\AA)$, C14-N22 (1.467 $\AA$ ) and in AAA

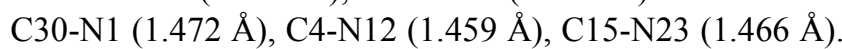
It appears that AAA has a bit longer averaged $\mathrm{C}-\mathrm{N}$ bond length compared to AA and A. Another bond which may be considered is the $\mathrm{O}-\mathrm{H}$ bond. In the monomer $\mathrm{A}$ the $\mathrm{O}-\mathrm{H}$ bond length ranges from 0.965 to $0.971 \AA$, in AA the range is 0.965-0.981 $\AA$, in AAA it is 0.969-0.991 $\AA$. The averaged value of $\mathrm{O}-\mathrm{H}$ internuclear separation is slightly increased again from $A$ to AAA.

Table 1. Geometrical parameters of the glucosamine monomer molecule A.

\begin{tabular}{llllll}
\hline Internuclear distance, $\boldsymbol{R}_{\mathbf{e}}, \boldsymbol{\AA}$ & Valence angle, $\mathbf{d e g}$. & & Torsion angle, $\mathbf{d e g}$. & Valence angle, deg. \\
\hline C4-O7 & 1.414 & C4-O7-C5 & 113.9 & C2-C5-O7-C4 & 57.9 \\
C5-O7 & 1.431 & C4-C3-C6 & 109.2 & C3-C4-O7-C5 & -59.8 \\
C2-C5 & 1.536 & C2-C6-C3 & 110.7 & C6-C2-C5-O7 & -52.8 \\
C2-C6 & 1.543 & C5-C2-C6 & 109.3 & C2-C6-C3-C4 & -55.1 \\
C3-C4 & 1.537 & C2-C5-O7 & 112.3 & C2-C5-C9-O10 & 67.7 \\
C3-C6 & 1.523 & C3-C4-O7 & 110.8 & C2-C6-C3-N11 & -178 \\
C6-O8 & 1.44 & C3-C6-O8 & 106.8 & O12-C2-C6-O8 & 46.7 \\
C2-O12 & 1.412 & C6-C2-O12 & 109.6 & C3-C6-C2-C5 & 52.6 \\
C5-C9 & 1.524 & C5-C2-O12 & 112.1 & C3-C6-C2-O12 & -70.6 \\
C3-N11 & 1.461 & O1-C4-O7 & 112.0 & C6-C2-C5-O8 & -52.8 \\
C-H & C4-C3-N11 & 111.9 & O7-C4-C3-C6 & 57.7 \\
O-H & 1.104 & C2-C5-C9 & 116.5 & & \\
\hline
\end{tabular}

Note: The averaged bond lengths are: $\mathrm{R}_{\mathrm{e}}(\mathrm{C}-\mathrm{H})=1.104 ; \mathrm{R}_{\mathrm{e}}(\mathrm{O}-\mathrm{H})=0.967 ; \mathrm{R}_{\mathrm{e}}(\mathrm{N}-\mathrm{H})=1.017 \AA$.

Table 2. Geometrical parameters of the glucosamine dimer molecule AA.

\begin{tabular}{|c|c|c|c|c|c|}
\hline \multicolumn{2}{|c|}{ Internuclear distance, $\boldsymbol{R}_{\mathrm{e}}, \AA$} & \multicolumn{2}{|c|}{ Valence angle, deg. } & \multirow{2}{*}{$\begin{array}{l}\text { Torsion angle, deg. } \\
\mathrm{C} 2-\mathrm{C} 5-\mathrm{O} 7-\mathrm{C} 4\end{array}$} & \multirow{2}{*}{$\begin{array}{l}\text { Valence angle, deg } \\
60.4\end{array}$} \\
\hline $\mathrm{C} 4-\mathrm{O} 7$ & 1.419 & $\mathrm{C} 4-\mathrm{O} 7-\mathrm{C} 5$ & 113.7 & & \\
\hline $\mathrm{C} 5-\mathrm{O} 7$ & 1.433 & $\mathrm{C} 4-\mathrm{C} 3-\mathrm{C} 6$ & 109.7 & $\mathrm{C} 3-\mathrm{C} 4-\mathrm{O} 7-\mathrm{C} 5$ & -60.8 \\
\hline $\mathrm{C} 15-\mathrm{O} 18$ & 1.423 & $\mathrm{C} 15-\mathrm{O} 18-\mathrm{C} 16$ & 114.2 & C13-C16-O18-C15 & 56.4 \\
\hline $\mathrm{C} 16-\mathrm{O} 18$ & 1.440 & $\mathrm{C} 15-\mathrm{C} 14-\mathrm{C} 17$ & 109.0 & C14-C15-O18-C16 & -59.0 \\
\hline $\mathrm{C} 2-\mathrm{C} 5$ & 1.535 & $\mathrm{C} 3-\mathrm{C} 6-\mathrm{C} 2$ & 110.2 & $\mathrm{C} 2-\mathrm{C} 6-\mathrm{C} 3-\mathrm{C} 4$ & -53.2 \\
\hline $\mathrm{C} 13-\mathrm{C} 16$ & 1.536 & $\mathrm{C} 13-\mathrm{C} 17-\mathrm{C} 14$ & 109.7 & C14-C17-C13-C16 & 54.2 \\
\hline C3-N11 & 1.457 & C4-C3-N11 & 112.2 & O7-C4-C3-N11 & 177.6 \\
\hline C14-N22 & 1.467 & $\mathrm{C} 15-\mathrm{C} 14-\mathrm{N} 22$ & 110.6 & O18-C15-C14-N22 & 179.6 \\
\hline $\mathrm{C} 2-\mathrm{O} 12$ & 1.438 & $\mathrm{C} 2-\mathrm{O} 12-\mathrm{C} 15$ & 119.1 & C6-C2-O12-C15 & -85.1 \\
\hline $\mathrm{C} 15-\mathrm{O} 12$ & 1.400 & & & $\mathrm{C} 2-\mathrm{O} 12-\mathrm{C} 15-\mathrm{C} 14$ & -138.1 \\
\hline $\mathrm{O} 18 \cdots \mathrm{H} 29$ & 1.929 & $\mathrm{O} 8-\mathrm{H} 29 \cdots \mathrm{O} 18$ & 159.2 & $\mathrm{C} 2-\mathrm{O} 12-\mathrm{C} 15-\mathrm{O} 18$ & 100.4 \\
\hline
\end{tabular}

Note: The averaged bond lengths are: $\mathrm{R}_{\mathrm{e}}(\mathrm{C}-\mathrm{H})=1.107 ; \mathrm{R}_{\mathrm{e}}(\mathrm{O}-\mathrm{H})=0.971 ; \mathrm{R}_{\mathrm{e}}(\mathrm{N}-\mathrm{H})=1.017 \AA$. 
Table 3. Geometrical parameters of the glucosamine trimer molecule AAA.

\begin{tabular}{|c|c|c|c|c|c|}
\hline \multicolumn{2}{|c|}{ Internuclear distance, $\boldsymbol{R}_{\mathrm{e}}, \AA$} & \multicolumn{2}{|c|}{ Valence angle, deg. } & \multirow{2}{*}{$\begin{array}{l}\text { Torsion angle, deg. } \\
\mathrm{C} 5-\mathrm{O} 8-\mathrm{C} 6-\mathrm{C} 3\end{array}$} & \multirow{2}{*}{$\begin{array}{l}\text { Valence angle, deg } \\
60.8\end{array}$} \\
\hline $\mathrm{C} 5-\mathrm{O} 8$ & 1.413 & $\mathrm{C} 5-\mathrm{O} 8-\mathrm{C} 6$ & 113.7 & & \\
\hline C6-O8 & 1.440 & $\mathrm{C} 3-\mathrm{C} 7-\mathrm{C} 4$ & 110.2 & $\mathrm{C} 4-\mathrm{C} 5-\mathrm{O} 8-\mathrm{C} 6$ & -60.5 \\
\hline C16-O19 & 1.424 & C16-O19-C17 & 114.3 & C16-O19-C17-C14 & 56.1 \\
\hline C17-O19 & 1.439 & $\mathrm{C} 14-\mathrm{C} 18-\mathrm{C} 15$ & 109.7 & C15-C16-O19-C17 & -58.8 \\
\hline $\mathrm{C} 28-\mathrm{O} 27$ & 1.400 & $\mathrm{C} 25-\mathrm{O} 27-\mathrm{C} 28$ & 119.9 & $\mathrm{C} 25-\mathrm{O} 27-\mathrm{C} 28-\mathrm{C} 30$ & 45.9 \\
\hline $\mathrm{C} 25-\mathrm{O} 27$ & 1.439 & $\mathrm{C} 26-\mathrm{C} 35-\mathrm{C} 30$ & 109.9 & $\mathrm{C} 26-\mathrm{C} 25-\mathrm{O} 27-\mathrm{C} 28$ & -52.1 \\
\hline $\mathrm{C} 3-\mathrm{C} 6$ & 1.533 & $\mathrm{C} 3-\mathrm{C} 7-\mathrm{C} 4$ & 110.2 & $\mathrm{C} 4-\mathrm{C} 7-\mathrm{C} 3-\mathrm{C} 6$ & 53.4 \\
\hline $\mathrm{C} 14-\mathrm{C} 17$ & 1.536 & C14-C18-C15 & 109.7 & C14-C18-C15-C26 & -57.8 \\
\hline $\mathrm{C} 25-\mathrm{C} 26$ & 1.541 & $\mathrm{C} 26-\mathrm{C} 31-\mathrm{C} 30$ & 109.9 & $\mathrm{C} 26-\mathrm{C} 31-\mathrm{C} 30-\mathrm{C} 28$ & 41.7 \\
\hline C4-N12 & 1.459 & C5-C4-N12 & 112.1 & O8-C5-C4-N12 & 177.4 \\
\hline $\mathrm{C} 15-\mathrm{N} 23$ & 1.466 & C16-C15-N23 & 110.6 & O19-C16-C15-N23 & 179.5 \\
\hline $\mathrm{C} 30-\mathrm{N} 1$ & 1.472 & C28-C30-N1 & 107.7 & $\mathrm{O} 27-\mathrm{C} 28-\mathrm{C} 30-\mathrm{N} 1$ & -162.2 \\
\hline $\mathrm{C} 5-\mathrm{O} 2$ & 1.408 & $\mathrm{C} 5-\mathrm{O} 2-\mathrm{C} 26$ & 116.9 & C7-C3-O13-C16 & -85.5 \\
\hline $\mathrm{C} 16-\mathrm{O} 13$ & 1.398 & $\mathrm{C} 3-\mathrm{O} 13-\mathrm{C} 16$ & 119.1 & C3-O13-C16-O19 & 99.7 \\
\hline C3-O13 & 1.439 & & & $\mathrm{C} 5-\mathrm{O} 2-\mathrm{C} 26-\mathrm{C} 31$ & -86.9 \\
\hline $\mathrm{O} 19 \cdots \mathrm{H} 58$ & 1.923 & 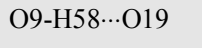 & 160.0 & $\mathrm{C} 26-\mathrm{O} 2-\mathrm{C} 5-\mathrm{C} 4$ & -160.3 \\
\hline $\mathrm{O} 29 \cdots \mathrm{H} 69$ & 1.768 & O34-H69 ․ O29 & 153.1 & $\mathrm{C} 26-\mathrm{O} 2-\mathrm{C} 5-\mathrm{O} 8$ & 76.3 \\
\hline $\mathrm{O} 34 \cdots \mathrm{H} 50$ & 1.735 & $\mathrm{O} 32-\mathrm{H} 50 \cdots \mathrm{O} 34$ & 163.0 & $\mathrm{C} 5-\mathrm{O} 2-\mathrm{C} 26-\mathrm{C} 25$ & 146.4 \\
\hline
\end{tabular}

Note: The averaged bond lengths are: $\mathrm{R}_{\mathrm{e}}(\mathrm{C}-\mathrm{H})=1.099 ; \mathrm{R}_{\mathrm{e}}(\mathrm{O}-\mathrm{H})=0.977 ; \mathrm{R}_{\mathrm{e}}(\mathrm{N}-\mathrm{H})=1.018 \AA$

The important feature in the dimer and trimer molecules is the appearance of the hydrogen bonds $\mathrm{O} \cdots \mathrm{H}-\mathrm{O}$. There are two types of hydrogen bonds may be considered, the first one is between two glucosamine molecules (intermolecular hydrogen bond) and the second type is within the glucosamine molecule (intra-molecular bond). Intermolecular hydrogen bonds were found both in the dimer and trimer molecules. In the $\mathrm{AA}$, this bond is $\mathrm{O} 8-\mathrm{H} 29 \cdots \mathrm{O} 18, R_{\mathrm{e}}(\mathrm{H} 29 \cdots \mathrm{O} 18)=1.929 \AA, \angle \mathrm{O} 8-\mathrm{H} 29 \cdots \mathrm{O} 18$ $=169^{\circ}$. In the AAA, the bond O19 $\cdots \mathrm{H} 58-\mathrm{O} 9, R_{\mathrm{e}}(\mathrm{H} 58 \cdots \mathrm{O} 19)$ $=1.923 \AA, \angle \mathrm{O} 19 \cdots \mathrm{H} 58-\mathrm{O} 9=160^{\circ}$ has been found, it is between the central ring and right-hand side one as is seen in Fig. 2 (c). The intra-molecular hydrogen bonds have been disclosed in the trimer molecule, they were O34-H69 $\cdots$ O 29 and $\mathrm{O} 32-\mathrm{H} 50 \cdots \mathrm{O} 34$ with $R_{\mathrm{e}}(\mathrm{H} 69 \cdots \mathrm{O} 29)=1.768 \AA$, $\angle \mathrm{O} 34-\mathrm{H} 69 \cdots \mathrm{O} 29=153^{\circ} ; R_{\mathrm{e}}(\mathrm{H} 50 \cdots \mathrm{O} 34)=1.735 \AA$, $\angle \mathrm{O} 32-\mathrm{H} 50 \cdots \mathrm{O} 34=163^{\circ}$, respectively. In Fig. 2 (c), these bonds are seen in the left-hand side ring. The other two rings of AAA do not possess the intra-molecular H-bonds. Neither monomer nor dimer has this type of bond. Thus the intra-molecular hydrogen bonds are shorter than intermolecular bonds by $\sim 0.2 \AA$. According to the IUPAC definition of hydrogen bond [15] the $\mathrm{X}-\mathrm{H} \cdots \mathrm{Y}$ angle is usually close to $180^{\circ}$. In our case the angles $\mathrm{O}-\mathrm{H} \cdots \mathrm{O}$ are less than $180^{\circ}$ due to the helicon structure of the glucosamine oligomers. Therefore the $\mathrm{H}$-bond formation favors the linkage between the glucosamine molecules, and along with the bending of the H-bond leads to the twisting of the oligomer chain.

\subsection{Vibrational Spectra}

The vibrational spectra of the monomer, dimer, and trimer glucosamine molecules were determined for the optimized geometrical configurations, true energy minima confirmed by the absence of imaginary frequencies. The vibrational analysis was done regarding the most common functional groups and structural components found in the three optimized structures. The theoretical spectra represented in Fig. 3 show a similar pattern: the three regions with significant absorption intensities are observed. The first region corresponds to $100-1660 \mathrm{~cm}^{-1}$ for A; 80-1660 for AA, and 80-1690 for AAA. The second region is 2920-3070 for A, 2930-3080 for AA, 2940-3140 for AAA; and the third one is 3740-3830 for A, 3490-3830 for AA, and $3340-3760 \mathrm{~cm}^{-1}$ for AAA. As is seen each of these three regions is expanding slightly in series A - AA - AAA. Experimental IR spectra of chitosan was obtained in [16-20] for the range between 750 and $4000 \mathrm{~cm}^{-1}$. According to the data reported, three main regions of absorption, $\sim 750-1700$ $\mathrm{cm}^{-1}, 2850-3000 \mathrm{~cm}^{-1}$, and $3100-3700 \mathrm{~cm}^{-1}$ may be observed. In this connection, our findings for the glucosamine molecules are in agreement with the experimental spectra of chitosan [19].

In the theoretical spectra, the characteristic vibrational modes can be considered regarding the functional groups of glucosamine. For the monomer molecule, the most intensive vibrations are found in the first low frequency region and correspond to the torsion vibrations involving $\mathrm{O}, \mathrm{N}$, and $\mathrm{C}$ atoms. Whereas both for the dimer and trimer molecules, the 
most intensive vibrations are observed in the third, high frequency, region and correspond to the stretching vibrations of the $\mathrm{N}-\mathrm{H}$, and $\mathrm{O}-\mathrm{H}$ groups, involving $\mathrm{H}$-bonds as well. The result on the $\mathrm{O}-\mathrm{H}$ frequencies in the dimer and trimer is in agreement with the experimental spectrum of chitosan, in
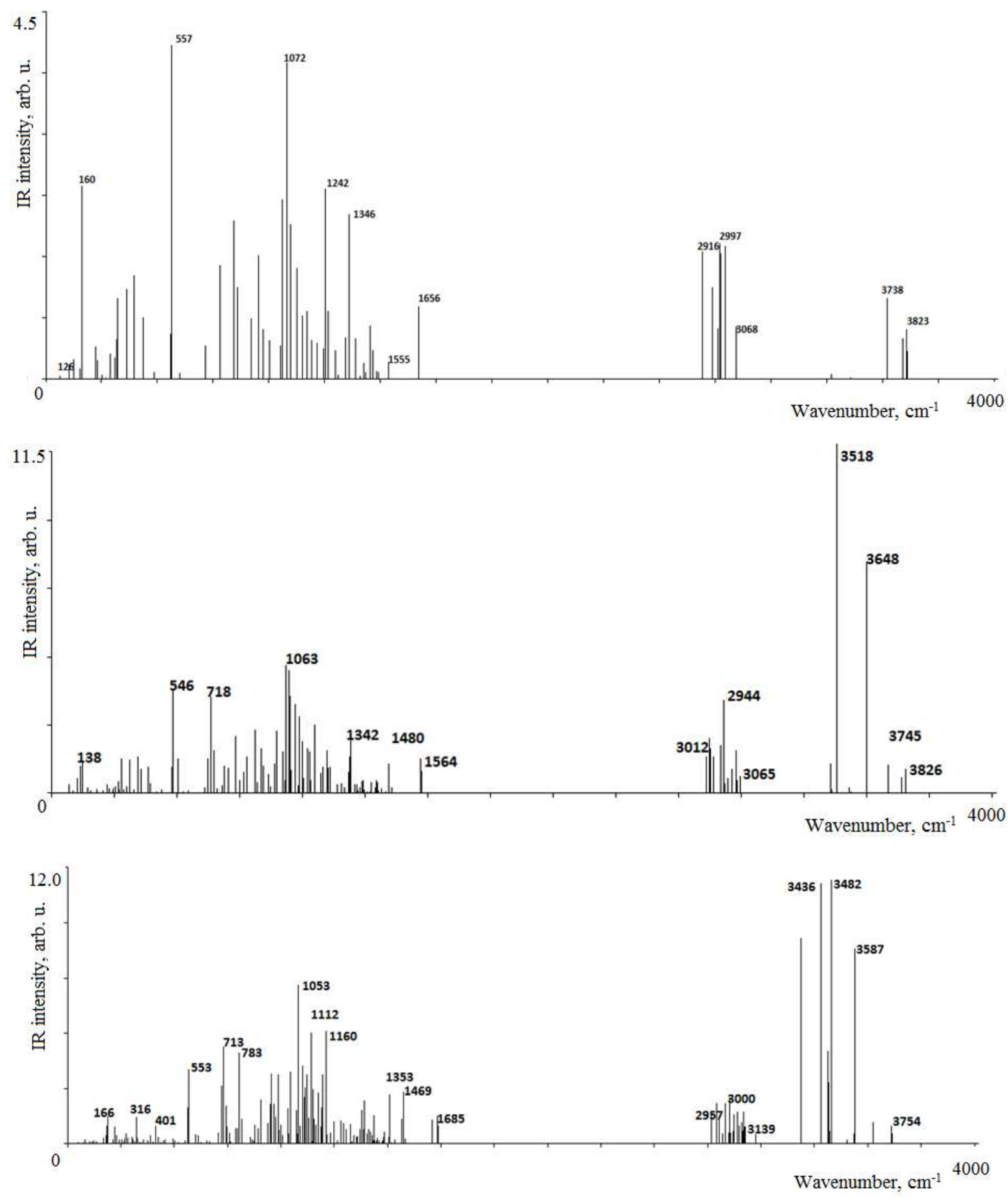

Figure 3. Theoretical IR spectra of the glucosamine molecules: monomer A (a); dimer AA (b), and trimer AAA (c).

which the most intensive and broad absorption band has been registered in the high frequency range with the peak at $3437.2 \mathrm{~cm}^{-1}$ for the O-H stretching mode [19]. The other characteristic frequencies in $\mathrm{A}$, AA, and AAA may be underlined. The bending vibrations of the amino groups correspond to $\sim 1660 \mathrm{~cm}^{-1}$ in all three molecules and it is in a agreement with the experimental value of $1594 \mathrm{~cm}^{-1}$ [19], but the intensities in the theoretical spectra are lower compared to the experimental ones and may be due to higher concentration of $\mathrm{NH}_{2}$-groups in the chitosan samples studied in [19]. 
Table 4. Thermodynamic functions of the glucosamine A, AA, and $A A A$.

\begin{tabular}{|c|c|c|c|c|}
\hline$T, \mathbf{K}$ & $C_{\mathrm{p}}^{\circ}, \mathrm{J} \cdot \mathrm{mol}^{-1} \cdot \mathrm{K}^{-1}$ & $S^{\circ}, \mathbf{J} \cdot \mathbf{m o l}^{-1} \cdot \mathbf{K}^{-1}$ & $\begin{array}{l}\Phi^{\circ}, \\
\mathbf{J} \cdot \mathbf{m o l}^{-1} \cdot \mathbf{K}^{-1}\end{array}$ & $\begin{array}{l}H^{\circ}(T)-H^{\circ}(0), \\
\mathrm{kJ} \cdot \mathrm{mol}^{-1}\end{array}$ \\
\hline \multicolumn{5}{|c|}{ Monomer A } \\
\hline 298 & 208.16 & 452.32 & 333.21 & 35.49 \\
\hline 300 & 209.29 & 453.71 & 334.01 & 35.91 \\
\hline 350 & 237.44 & 488.10 & 353.58 & 47.08 \\
\hline 400 & 264.41 & 521.58 & 372.48 & 59.64 \\
\hline 450 & 289.52 & 554.20 & 390.88 & 73.49 \\
\hline 500 & 312.48 & 585.91 & 408.81 & 88.55 \\
\hline 550 & 333.25 & 616.68 & 426.30 & 104.71 \\
\hline 600 & 352.00 & 646.50 & 443.43 & 121.84 \\
\hline \multicolumn{5}{|c|}{ Dimer AA } \\
\hline 298 & 386.17 & 662.92 & 450.51 & 63.30 \\
\hline 300 & 388.43 & 665.51 & 451.94 & 64.07 \\
\hline 350 & 444.37 & 729.47 & 486.91 & 84.90 \\
\hline 400 & 497.81 & 792.47 & 521.31 & 108.46 \\
\hline 450 & 547.41 & 854.01 & 554.87 & 134.61 \\
\hline 500 & 592.61 & 914.06 & 587.80 & 163.13 \\
\hline 550 & 633.40 & 972.49 & 620.13 & 193.80 \\
\hline 600 & 670.12 & 1029.21 & 651.87 & 226.40 \\
\hline \multicolumn{5}{|c|}{ Trimer AAA } \\
\hline 298 & 555.13 & 880.42 & 580.01 & 89.52 \\
\hline 300 & 558.5 & 884.15 & 582.02 & 90.64 \\
\hline 350 & 642.08 & 976.55 & 631.80 & 120.66 \\
\hline 400 & 722.04 & 1067.56 & 680.60 & 154.78 \\
\hline 450 & 796.36 & 1156.95 & 728.57 & 192.77 \\
\hline 500 & 864.16 & 1244.43 & 775.81 & 234.31 \\
\hline 550 & 925.44 & 1329.71 & 822.30 & 279.08 \\
\hline 600 & 980.64 & 1412.65 & 868.06 & 326.75 \\
\hline
\end{tabular}

The second region of the spectra is assigned to the $\mathrm{C}-\mathrm{H}$ stretching vibrations which is the same by the frequencies for monomer and dimer molecule but with a bit higher frequencies and broadening of the band for trimer. For $\mathrm{CH}_{2}$ bend modes which appear in the first region, the frequencies are in the range 1479-1523 in A and AA, and a bit higher $1512-1539 \mathrm{~cm}^{-1}$ in AAA. This result of the increasing of stretching and bending vibrational frequencies in the trimer molecule can be explained in terms of the strengthening of the $\mathrm{C}-\mathrm{H}$ bonds in the formation of AAA structure. This suggestion is supported by the decreasing of the averaged $\mathrm{C}-\mathrm{H}$ bond in AAA by $0.005 \AA$ compared to A or $0.008 \AA$ compared to AA.

For the AA and AAA, the second spectral region contains as well the intensive modes about $1050 \mathrm{~cm}^{-1}$ which is assigned to $\mathrm{C}-\mathrm{O}-\mathrm{C}$ glycosidic bonds. Other intensive lines near $715 \mathrm{~cm}^{-1}$ are assigned to the deformational modes of $\mathrm{H}-\mathrm{O} \cdots \mathrm{H}$ fragments with the hydrogen bonds. No such bands were noted in the experimental spectrum of chitosan. The difference between the theoretical and the experimental results may be attributed partially to difference in phases used. The experimental values are obtained for the solid phase while the theoretical values are computed for the gaseous phase of glucosamine.

\subsection{Thermodynamic Functions}

The thermodynamic functions of the momomer A, dimer $\mathrm{AA}$, and trimer AAA glucosamine molecules were calculated on the base of the vibrational frequencies and optimized geometrical coordinates in the rigid rotator - harmonic oscillator approximation using Openthermo computation package [21]. For temperature interval between 298-600 K, the molar heat capacity $C_{\mathrm{p}}^{\circ}$; the Gibbs reduced free energy $\Phi^{\circ}$; the entropy $S^{\circ}$; and the enthalpy increment $H^{\circ}(T)-H^{\circ}(0)$ are listed in Table 4 . The thermodynamic functions may be requested for the treatment of the experimental data on the evaporation of chitosan at elevated temperatures.

\subsection{Association Reactions of Glucosamine Molecules}

The association reactions of the glucosamine molecules resulting in the dimer AA and trimer AAA molecules have been considered. The reaction equations (I-III), the energies of the reactions $\Delta_{\mathrm{r}} E$, zero point vibrational energy correction $\triangle$ ZPVE and enthalpies of the reactions $\Delta_{r} H^{\circ}(0 \mathrm{~K})$ are given in Table 5. The formation of the trimer molecule may be represented through the reaction (II) as the attachment of the monomer molecule to dimer or through reaction (III) as the association of three monomers. The third reaction is an auxiliary one, as it is in fact the combination of the first and second reactions.

The energies of the reactions were found trough the total energy of the products and reactants:

$$
\Delta_{\mathrm{r}} E=E_{\text {prod }}-E_{\text {react }}
$$

The enthalpies of a reaction were calculated using the following equations:

$$
\Delta_{\mathrm{r}} H^{\mathrm{o}}(0 \mathrm{~K})=\Delta_{\mathrm{r}} E+\Delta \mathrm{ZPVE},
$$




$$
\Delta \mathrm{ZPVE}=(1 / 2) h c\left(\Sigma \omega_{i \text { prod }}-\Sigma \omega_{i \text { react }}\right)
$$

where $\Sigma \omega_{i}$ prod, $\Sigma \omega_{i}$ react are the sums of the vibration frequencies of the products and reactants, respectively.

The results have been obtained using different basis sets, $6-31 \mathrm{G}(\mathrm{d}, \mathrm{p}), 6-31 \mathrm{G}++(\mathrm{d}, \mathrm{p}), 6-311 \mathrm{G}++(\mathrm{d}, \mathrm{p})$. For the second and third basis sets the diffused functions have been added for the $\mathrm{H}, \mathrm{O}$, and $\mathrm{N}$ atoms. As is seen from Table 5, the both reactions for the dimer and trimer formations are exothermic. The implication of the diffuse functions brings to less negative values of the enthalpies of the reactions and the most remarkable change is observed for the trimerization reaction. So for the basis set $6-31 \mathrm{G}++(\mathrm{d}, \mathrm{p})$, the change in the values of $\Delta_{\mathrm{r}} H^{\mathrm{o}}(0 \mathrm{~K})$ is $\sim 6 \mathrm{~kJ} \cdot \mathrm{mol}^{-1}$ for the reaction (I) and $26 \mathrm{~kJ} \cdot \mathrm{mol}^{-1}$ for the reaction (II) compared to the results by the basis set $6-31 G(d, p)$. The further extending of the basis set through the splitting does not give essential difference in the enthalpies of the reactions.

Table 5. The reaction equations, energies $\Delta_{\mathrm{r}}$ E, zero point vibrational energy corrections $\Delta \mathrm{ZPVE}$ and enthalpies $\Delta_{\mathrm{r}} H^{\mathrm{o}}(0 \mathrm{~K})$.of the reactions.

\begin{tabular}{|c|c|c|c|c|c|}
\hline No & Reaction & Basis set & $\Delta_{\mathrm{r}} E, \mathrm{~kJ} \cdot \mathrm{mol}^{-1}$ & $\Delta \mathrm{ZPVE}, \mathrm{kJ} \cdot \mathrm{mol}^{-1}$ & $\Delta_{\mathrm{r}} \boldsymbol{H}^{0}(\mathbf{0} \mathrm{K}), \mathrm{kJ} \cdot \mathrm{mol}^{-1}$ \\
\hline \multirow{3}{*}{ I } & \multirow{3}{*}{$2 \mathrm{~A}=\mathrm{AA}+\mathrm{H}_{2} \mathrm{O}$} & $6-31 G(d, p)$ & -52.2 & -2.1 & -54.3 \\
\hline & & $6-31++G(d, p)$ & -46.4 & -2.1 & -48.5 \\
\hline & & $6-311++G(d, p)$ & -45.6 & -2.1 & -47.7 \\
\hline \multirow{3}{*}{ II } & \multirow{3}{*}{$\mathrm{AA}+\mathrm{A}=\mathrm{AAA}+\mathrm{H}_{2} \mathrm{O}$} & $6-31 G(d, p)$ & -69.9 & 3.5 & -66.4 \\
\hline & & $6-31++G(d, p)$ & -44.1 & 3.5 & -40.6 \\
\hline & & $6-311++G(d, p)$ & -48.7 & 3.5 & -45.2 \\
\hline \multirow{3}{*}{ III } & \multirow{3}{*}{$3 \mathrm{~A}=\mathrm{AAA}+2 \mathrm{H}_{2} \mathrm{O}$} & $6-31 \mathrm{G}(\mathrm{d}, \mathrm{p})$ & -122.1 & 1.5 & -120.6 \\
\hline & & $6-31++G(d, p)$ & -90.5 & 1.5 & -89.0 \\
\hline & & $6-311++\mathrm{G}(\mathrm{d}, \mathrm{p})$ & -94.3 & 1.5 & -92.8 \\
\hline
\end{tabular}

The recommended values of $\Delta_{\mathrm{r}} H^{\mathrm{o}}(0 \mathrm{~K})$ according to the calculations in the most extended basis set $6-311 \mathrm{G}++(\mathrm{d}, \mathrm{p})$ are -48 and $-45 \mathrm{~kJ} \cdot \mathrm{mol}^{-1}$ for the reaction (I) and (II) respectively. This implies that attachment energies of the glucosamine molecule to the monomer or dimer are comparable. We suggest that the attachment of the next glucosamine molecule to the trimer will bring the further stabilization of the larger oligomers and facilitate molecular chain formation.

\section{Conclusion}

The equilibrium geometrical parameters were obtained by DFT/B3LYP method for the monomer, dimer, and trimer glucosamine molecules. In the dimer and trimer molecules, the glycosidic bond links two neighboring non planar six-atomic-cycles. The hydrogen bonds were shown to exist in the dimer and trimer molecules and favor the strengthening of the oligomers' structure. The calculated vibrational spectra with the typical characteristic modes of the functional groups of glucosamine were proved to be in accordance with the reference experimental spectra of the deacetylated chitosan. The enthalpies of the dimerization and trimerization reactions of the glucosamine molecules were found and it appeared that these values were comparable.

\section{Acknowledgment}

The authors are grateful to The Nelson Mandela African Institution of Science and Technology (NM-AIST) for the sponsorship and also acknowledge the valuable assistance and service by the School of Computational and Communicational Science and Engineering at NM-AIST.

\section{References}

[1] J. Venkatesan and S.-K. Kim, "Chitosan composites for bone tissue engineering-An overview," Marine drugs, vol. 8, pp. 2252-2266, 2010.

[2] N. V. Toan, "Production of Chitin and Chitosan from Partially Autolyzed Shrimp Shell Materials," The Open Biomaterials Journal, vol. 1, pp. 21-24, 2009.

[3] I. Aranaz, M. Mengíbar, R. Harris, I. Paños, B. Miralles, N. Acosta, et al., "Functional characterization of chitin and chitosan," Current Chemical Biology, vol. 3, pp. 203-230, 2009.

[4] K. Desai, K. Kit, J. Li, P. Michael Davidson, S. Zivanovic, and H. Meyer, "Nanofibrous chitosan non-wovens for filtration applications," Polymer, vol. 50, pp. 3661-3669, 2009.

[5] M. Benavente, "Adsorption of metallic ions onto chitosan: equilibrium and kinetic studies," pp. 1654-1081, 2008.

[6] E. S. Abdou, K. S. A. Nagy, and M. Z. Elsabee, "Extraction and characterization of chitin and chitosan from local sources," Bioresource Technology, vol. 99, pp. 1359-1367, 2008.

[7] A. H. Lu, E. L. Salabas, and F. Schüth, "Magnetic nanoparticles: synthesis, protection, functionalization, and application," Angewandte Chemie International Edition, vol. 46, pp. 1222-1244, 2007.

[8] A. Fattahi, M. Ghorat, A. Pourjavadi, M. Kurdtabar, and A. Torabi, "DFT/B3LYP Study of Thermochemistry of D-Glucosamine, a Representative Polyfunctional Bioorganic Compound," Scientia Iranica, vol. 15, pp. 422-429, 2008.

[9] R. Terreux, M. Domard, C. Viton, and A. Domard, "Interactions study between the copper II ion and constitutive elements of chitosan structure by DFT calculation," Biomacromolecules, vol. 7, pp. 31-37, 2006. 
[10] A. A. Granovsky, "Firefly version 8.0.0," www http://classic.chem.msu.su/gran/firefly/index.html.

[11] K. K. B. M.W. Schmidt, J.A. Boatz, S.T. Elbert, M.S. Gordon, J.H. Jensen, S. Koseki, N. Matsunaga, K.A. Nguyen, S. Su, T.L. Windus, M. Dupuis, J.A. Montgomery., J. Comput. Chem. , pp. 1347-1363, 1993.

[12] wxMaclPlt. https://code.google.com/p/wxmacmolplt/wiki/Description.

[13] A. Domard and M. Domard, "Chitosan: structure-properties relationship and biomedical applications," Polymeric biomaterials, vol. 2, pp. 187-212, 2001.

[14] F.-C. Liu, C.-R. Su, T.-Y. Wu, S.-G. Su, H.-L. Yang, J. H.-Y. Lin, et al., "Efficient 1H-NMR Quantitation and Investigation of N-Acetyl-D-glucosamine (GlcNAc) and $\mathrm{N}$, N'-Diacetylchitobiose (GlcNAc) 2 from Chitin," International journal of molecular sciences, vol. 12, pp. 5828-5843, 2011.

[15] E. Arunan, G. R. Desiraju, R. A. Klein, J. Sadlej, S. Scheiner, I. Alkorta, et al., "Definition of the hydrogen bond (IUPAC Recommendations 2011)," Pure and applied chemistry, vol. 83, pp. 1637-1641, 2011.
[16] J. Brugnerotto, J. Lizardi, F. M. Goycoolea, W. Argüelles-Monal, J. Desbrieres, and M. Rinaudo, "An infrared investigation in relation with chitin and chitosan characterization," Polymer, vol. 42, pp. 3569-3580, 2001.

[17] G. Cardenas and S. P. Miranda, "FTIR and TGA studies of chitosan composite films," Journal of the Chilean Chemical Society, vol. 49, pp. 291-295, 2004.

[18] J. Kumirska, M. Czerwicka, Z. Kaczyński, A. Bychowska, K. Brzozowski, J. Thöming, Piotr Stepnowski, "Application of spectroscopic methods for structural analysis of chitin and chitosan," Marine drugs, vol. 8, pp. 1567-1636, 2010.

[19] S. Kunjachan, S. Jose, and T. Lammers, "Understanding the mechanism of ionic gelation for synthesis of chitosan nanoparticles using qualitative techniques," Asian journal of pharmaceutics, vol. 4, p. 148, 2010.

[20] A. T. Paulino, J. I. Simionato, J. C. Garcia, and J. Nozaki, "Characterization of chitosan and chitin produced from silkworm crysalides," Carbohydrate Polymers, vol. 64, pp. 98-103, 2006

[21] K. Tokarev, "OpenThermo ", v.1.0 Beta 1 (C) ed. http://openthermo.software.informer.com/, 2007-2009. 